\title{
Preparation of Silver-Montmorillonite Nanocomposites by Reduction with Formaldehyde and Borohydride
}

\author{
Petr Praus, ${ }^{*, a}$ Martina Turicováa ${ }^{a}$ and Mariana Klementová ${ }^{b}$ \\ ${ }^{a}$ Department of Analytical Chemistry and Material Testing, VŠB-Technical University of Ostrava, 17, \\ listopadu 15, 70833 Ostrava-Poruba, Czech Republic \\ ${ }^{b}$ Institute of Inorganic Chemistry of the ASCR, v.v.i., 25068 Husinec-Řež 1001, Czech Republic
}

\begin{abstract}
Montmorilonita rica em sódio (MMT) foi intercalada com cátions prata, os quais foram subsequentemente reduzidos com formaldeído ou boroidreto de sódio. Os nanocompostos prata-montmorilonita foram estudados por espectrometria UV-Vis, microscopia eletrônica de transmissão (TEM) e difratometria de raios-X (XRD). A influência de diferentes agentes redutores na dispersão e no tamanho das partículas de prata depositadas na superfície da montmorilonita foi investigada. A redução com boroidreto produziu partículas de prata dispersas uniformemente, com tamanhos limitados entre 3 e $13 \mathrm{~nm}$. A redução com formaldeído gerou partículas dispersas irregularmente com uma distribuição de tamanho muito maior, variando entre 3 e $100 \mathrm{~nm}$. Além disso, entre as partículas de prata preparadas por redução com formaldeído, algumas partículas de $\mathrm{Ag}_{2} \mathrm{O}$ foram obtidas como resultado de redução incompleta. Os compósitos de prata-montmorilonita preparados por redução com boroidreto e formaldeído contêm $2,4 \%$ e 5,3\% em massa de $\mathrm{Ag}$, respectivamente.
\end{abstract}

Na-rich montmorillonite (MMT) was intercalated with silver cations, which were subsequently reduced with formaldehyde or sodium borohydride. The silver-montmorillonite nanocomposites were studied by UV-visible spectrometry, transmission electron microscopy (TEM) and X-ray diffractometry (XRD). The influence of different reducing agents on the dispersity and size of silver particles deposited on montmorillonite surface was investigated. The reduction with borohydride gives rise to uniformly dispersed silver particles with a narrow particle size distribution from $3 \mathrm{~nm}$ to $13 \mathrm{~nm}$. Formaldehyde reduction forms unevenly dispersed particles with a much wider size distribution, ranging from 3 to $100 \mathrm{~nm}$. In addition, some $\mathrm{Ag}_{2} \mathrm{O}$ particles were found among silver particles prepared with formaldehyde, likely as a result of incomplete reduction. Silvermontmorillonite composites prepared by reduction with borohydride and formaldehyde contain $2.4 \mathrm{wt} \%$ and $5.3 \mathrm{wt} \%$ of $\mathrm{Ag}$, respectively.

Keywords: silver, nanocomposites, montmorillonite, reduction, formaldehyde, borohydride

\section{Introduction}

Silver nanocomposites are used for many industrial applications, such as resonant and nonlinear optical elements, high-dielectric strength media for capacitors, enhanced electrical conductivity of ceramic media, pattern etching using HF, augmentation of electrode response, magnetic spin glasses, etc. A variety of conventional solgel preparation methods exists for Ag-nanocomposites fabrication, either as bulk powder or thin films, using organically modified gels or gel precursors. ${ }^{1,2}$ Another

*e-mail: petr.praus@vsb.cz type of Ag-nacomposites are silver nanoparticles deposited on inorganic platforms, such as $\mathrm{Al}_{2} \mathrm{O}_{3}, \mathrm{SiO}_{2}, \mathrm{SiO}_{2} / \mathrm{B}_{2} \mathrm{O}_{3}$, $\mathrm{SiO}_{2} / \mathrm{TiO}_{2}, \mathrm{TiO}_{2}, \mathrm{BaTiO}_{3}$, etc. ${ }^{1}$ Phyllosilicates, such as montmorillonite ${ }^{2-4}$ and kaolinite, ${ }^{5}$ have been also used as carriers for silver particles.

For the preparation of Ag-nanocomposites, silver nitrate is often used as the primary source of silver ions. There are several ways of $\mathrm{Ag}^{+}$reduction: use of gamma, ${ }^{6} \mathrm{UV},{ }^{7}$ or femtosecond laser irradiations, ${ }^{8}$ heating, ${ }^{9}$ electrochemical reduction, ${ }^{10}$ application of reducing chemicals, such as hydrazine, ${ }^{11}$ sodium borohydride, ${ }^{5}$ glycerol, ${ }^{3,12} \mathrm{~N}, \mathrm{~N}$ dimethylformamide, ${ }^{13}$ glucose, ${ }^{14}$ ethylene glycol, ${ }^{4}$ folmadehyde, ${ }^{15,16}$ sodium in liquid ammonia, ${ }^{17}$ etc. In 
addition, reduction of $\left[\mathrm{Ag}\left(\mathrm{NH}_{3}\right)_{2}\right]^{+}$by various saccharides was described by Panáček et al. ${ }^{18}$

The aim of this work was to prepare a temperature-stable silver nanocomposite consisting of silver nanoparticles deposited on an inorganic carrier. For this purpose, silver ions were adsorbed on monmorillonite (MMT) and reduced by borohydride or formaldehyde. The size and dispersity of silver particles located on the phyllosilicate surface were studied. The development of methods for the preparation of silver nanoparticles of required diameter ranges is desired.

\section{Experimental}

\section{Nanocomposite preparation}

\section{Reagents}

All chemicals were of analytical reagent grade: formalin (37\%), sodium hydroxide, triethanolamine (TEA), sodium bicarbonate (Lachema, Czech Republic) and sodium borohydride $\left(\mathrm{NaBH}_{4}\right.$, Merck, Germany). Water used for the preparation of solutions was deionised by reverse osmosis.

\section{Adsorption procedure}

$\mathrm{Na}^{+}$-rich montmorillonite SWy 2 (Crook County, Wyoming) with exchange capacity of 1.2 mequiv $\mathrm{g}^{-1}$, determined by saturation with $\mathrm{NH}_{4}^{+19}$ and by analysis of released metals $\left(\mathrm{Na}^{+}, \mathrm{K}^{+}, \mathrm{Ca}^{2+}, \mathrm{Mg}^{2+}\right)$, was used for the adsorption of silver cations. The MMT formula is $\mathrm{Na}_{0.38}$ $\mathrm{K}_{0.04}\left(\mathrm{Ca}_{0.12} \mathrm{Mg}_{0.50} \mathrm{Fe}^{3+}{ }_{0.41} \mathrm{Al}_{2.90} \mathrm{Ti}_{0.01} \mathrm{Mn}_{0.01}\right) \mathrm{Si}_{8} \mathrm{O}_{20}(\mathrm{OH})_{4}$, as calculated from the results of X-ray fluorescence analysis. A fraction of MMT (particle size $<5 \mu \mathrm{m}$ ) separated by sedimentation was used.

The adsorption procedure was adopted from our recent work. ${ }^{2}$ A portion of MMT (about $0.1 \mathrm{~g}$ ) was added into $100 \mathrm{~mL}$ of $0.010 \mathrm{~mol} \mathrm{~L}^{-1} \mathrm{AgNO}_{3}$ solution and this suspension was shaken vigorously for $24 \mathrm{~h}$. The suspension was then centrifuged (4500 $\mathrm{min}^{-1}$ ) for $20 \mathrm{~min}$, filtered through $1.2 \mu \mathrm{m}$ glass fibre filters (Whatman), and dried gently at $50{ }^{\circ} \mathrm{C}$ for $24 \mathrm{~h}$. All experiments were performed at room temperature varied from $20^{\circ} \mathrm{C}$ to $24^{\circ} \mathrm{C}$. Montmorillonite containing silver ions is labelled $\mathrm{Ag}^{+}-\mathrm{MMT}$.

\section{Reduction procedure}

Two procedures for silver reduction were tested: the reduction with formaldehyde and the reduction with $\mathrm{NaBH}_{4}$. Formaldehyde reduction consisted of the following steps: (i) $10 \mathrm{mg}$ of $\mathrm{Ag}^{+}$-MMT were placed into a test tube, (ii) $5 \mathrm{~mL}$ of $0.37 \%$ formaldehyde solution and (iii) $0.5 \mathrm{~mL}$ of alkaline reagent $\left(\mathrm{NaOH}, \mathrm{NaHCO}_{3}\right.$, TEA) were added, and the suspension was mixed and shaken. For the reduction with $\mathrm{NaBH}_{4}, 10 \mathrm{mg}$ of $\mathrm{Ag}^{+}-\mathrm{MMT}$ were placed into a test tube and $5 \mathrm{~mL}$ of $\mathrm{NaBH}_{4}$ solution $\left(0.010 \mathrm{~mol} \mathrm{~L}^{-1}\right)$ were added and shaken. ${ }^{2}$ This reaction is vigorous and takes only several min. Ag-MMT suspensions were analysed by UV-visible spectrometry.

After reduction, Ag-MMT was filtered out through $1.2 \mu \mathrm{m}$ glass fibre filters and washed several times with water to remove residual $\mathrm{Ag}^{+}$ions, which were then analysed in the filtrates by silver electrode (Theta 90, Czech Republic). Silver was also analysed in the filtrates, after dissolution with $\mathrm{HNO}_{3}$, by atomic absorption spectrometry (see below). Silver particles adsorbed on MMT were further studied by transmission electron microscopy and X-ray powder diffraction.

Ag-montmorillonite composites prepared with borohydride were labelled as Ag-MMT/ $\mathrm{NaBH}_{4}$, while those prepared with formaldehyde were labelled as Ag-MMT/F. The products of reduction with formaldehyde were also labelled as F-NaOH, F-NaHCO 3 and F-TEA, depending on the alkaline reagent used.

\section{Characterization methods}

\section{$U V$-visible absorption spectrometry}

UV-visible absorption spectra were measured with a Lambda 25 double-beam spectrometer (Perkin Elmer, USA). All spectra were recorded using $1 \mathrm{~cm}$ quartz cuvettes within the range of $200 \mathrm{~nm}$ to $800 \mathrm{~nm}$. The cuvettes were filled with shaken suspensions and the spectra of MMT, $\mathrm{Ag}^{+}-\mathrm{MMT}$ and Ag-MMT were recorded immediately against distilled water.

\section{Atomic absorption spectrometry}

An atomic absorption spectrometer Spectra AA30 (Varian Inc., USA) was used for the determination of silver in the filtrates using a standardised method. ${ }^{20}$ Air-acetylene flame was employed as the atomisation technique.

\section{Transmission electron microscopy}

Transmission electron microscopy analysis was carried out on a JEOL JEM 3010 microscope operated at $300 \mathrm{kV}\left(\mathrm{LaB}_{6}\right.$ cathode, point resolution $0.17 \mathrm{~nm}$ ) with an EDX (Energy Dispersive X-ray) detector attached. Images were recorded on a CCD camera with the resolution of $1024 \times 1024$ pixels using the Digital Micrograph software package.

Powder samples were dispersed in ethanol and the suspension was treated with ultrasound for $10 \mathrm{~min}$. A drop of a very dilute suspension was placed on a holey-carboncoated copper grid and allowed to dry by evaporation at room temperature. Selected-area electron diffraction 
(SAED) patterns were analyzed using the Process Diffraction software package. ${ }^{21}$

\section{$X$-ray powder diffraction}

The X-ray powder diffraction study was performed using a powder diffractometer INEL CPS 120 (INEL, France) equipped with a curved position-sensitive detector PSD 120 $\mathrm{MB} / 11$ (reflection mode, Ge-monochromatized, $\mathrm{Cu}-\mathrm{K}_{\alpha 1}$ radiation), which allows simultaneous data collection over $0^{\circ}$ to $120^{\circ}$ with steps of $0.031^{\circ}$ in 2 -theta. The diffraction patterns were acquired in ambient atmosphere under constant conditions (2000 s, $35 \mathrm{kV}, 20 \mathrm{~mA}$ ).

\section{Statistical software}

All statistical calculations were made at $\alpha=0.05$ significance level by the program QC.Expert 2.5 (Trilobyte Statistical Software, Ltd., Czech Republic).

\section{Results and Discussion}

In the first step of nanocomposite preparation, silver cations were adsorbed on montmorillonite $\left(\mathrm{Ag}^{+}-\mathrm{MMT}\right)$ by shaking in $\mathrm{AgNO}_{3}$ solution for $24 \mathrm{~h}$. Thereafter, $\mathrm{Ag}^{+}-\mathrm{MMT}$ was filtered out and dried, and silver cations were reduced by addition of aqueous solutions of formaldehyde or sodium borohydride.

\section{Reduction of silver ions}

The reduction with formaldehyde is described by the following reactions: $:^{14,22}$

$$
\begin{aligned}
& 2 \mathrm{Ag}^{+}+2 \mathrm{OH}^{-} \rightleftharpoons \mathrm{Ag}_{2} \mathrm{O}+\mathrm{H}_{2} \mathrm{O} \\
& \mathrm{Ag}_{2} \mathrm{O}+\mathrm{HCHO} \rightleftharpoons 2 \mathrm{Ag}+\mathrm{HCOOH}
\end{aligned}
$$

Alkaline conditions, which are essential for reaction 1, were provided by addition of sodium hydroxide, sodium bicarbonate or triethanolamine (TEA).

The reduction with borohydride consists of (i) in-situ generation of hydrogen by the decomposition of $\mathrm{NaBH}_{4}$ and (ii) reaction of hydrogen and silver ions: ${ }^{2}$

$$
\begin{aligned}
& 2 \mathrm{H}_{2} \mathrm{O}+\mathrm{BH}_{4}^{-} \rightleftharpoons 4 \mathrm{H}_{2}+\mathrm{BO}_{2}^{-} \\
& 2 \mathrm{Ag}^{+}+\mathrm{H}_{2} \rightleftharpoons 2 \mathrm{Ag}+2 \mathrm{H}^{+}
\end{aligned}
$$

No other additives are necessary. Ag-MMT composites were separated from the dispersions by filtration (see
Experimental). The efficiency of the reduction was determined by electrochemical analysis of residual silver cations in the filtrates with a silver electrode. The limit of quantification (LOQ) of the method was estimated at $1 \times 10^{-6} \mathrm{~mol} \mathrm{~L}^{-1}$ of $\mathrm{Ag}^{+}$, which corresponds to $0.02 \mathrm{wt} \%$ of silver in Ag-MMT. The concentrations of residual $\mathrm{Ag}^{+}$were lower than LOQ in all filtrates. It corresponds to a reduction efficiency $\geq 99.98 \%$.

The content of silver in each Ag-MMT composite was determined by AAS after its dissolution in a mixture of $\mathrm{HF}, \mathrm{HNO}_{3}$ and $\mathrm{HClO}_{4}(5: 4: 4){ }^{23}$ The reproducibility of the Ag-MMT preparation was estimated at $2.6 \%$. The amount of Ag in Ag-MMT significantly depends on the reducing reagent used. While using borohydride, $2.4 \mathrm{wt} \%$ $\mathrm{Ag}\left(0.22 \mathrm{mmol} \mathrm{g}^{-1}\right)$ was found. The content of Ag formed by formaldehyde was similar in all Ag-MMT samples regardless of the employed alkaline agent, i.e., $5.3 \mathrm{wt} \%$ $\left(0.49 \mathrm{mmol} \mathrm{g}^{-1}\right)$. This difference is given by the size of silver particles. Small Ag particles of Ag-MMT/NaBH probably passed through the filter pores into the filtrates in higher amounts than those of Ag-MMT/F. This was also confirmed by TEM (see below) and by analysis of Ag in the filtrates. A higher content of Ag in Ag-MMT should be achieved by filtration through denser filters.

\section{UV-visible absorption study}

It is well known that the surface plasmon of silver nanosized particles exhibits a characteristic adsorption band around $410 \mathrm{~nm}$. Therefore, the optimal reaction time and concentrations of all reagents could be tuned by recording the UV-visible absorption spectra of $\mathrm{Ag}^{+}-\mathrm{MMT}$ suspensions.

The initial concentrations of $\mathrm{NaOH}$ and $\mathrm{NaHCO}_{3}$ were $0.010,0.050,0.10$, and $0.20 \mathrm{~mol} \mathrm{~L}^{-1}$. Solutions of TEA had concentrations of $0.010,0.050$ and $0.10 \mathrm{~mol} \mathrm{~L}^{-1}$. UV-visible spectra were measured after $0.5,1,2$, and $4 \mathrm{~h}$. Absorbance was measured at the absorption band maxima $\left(\lambda_{\max }\right)$.

Graphs showing the changes of absorbance versus reaction time are shown in Figures 1a-c. In the case of formaldehyde, the absorbance increases during the first two hours and then stays nearly constant. Therefore, two hours were selected as the sufficient reaction time for the quantitative reduction. The optimum concentrations of the bases were chosen so that the highest reduction efficiency, expressed by the highest absorbance around $410 \mathrm{~nm}$, was reached: $0.10 \mathrm{~mol} \mathrm{~L}^{-1}$ for both $\mathrm{NaOH}$ and $\mathrm{NaHCO}_{3}$, and $0.50 \mathrm{~mol} \mathrm{~L}^{-1}$ for TEA. At the higher concentrations, the absorption band becomes lower and broader. The optimum conditions for the reduction with borohydride $\left(0.01 \mathrm{~mol} \mathrm{~L}^{-1}\right)$ have been studied recently. ${ }^{2}$ 
(a)

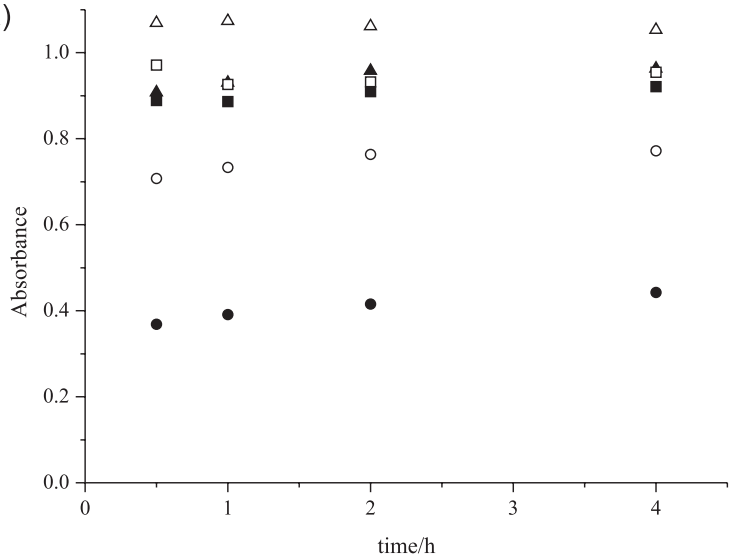

(b)

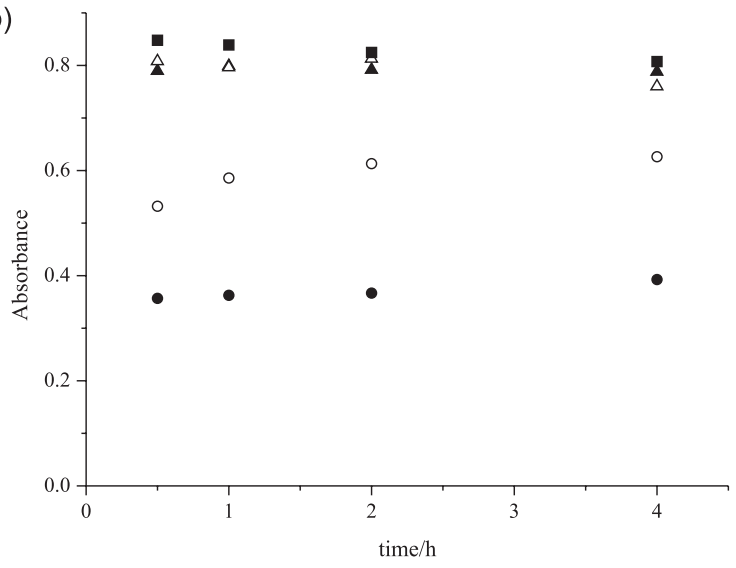

(c)

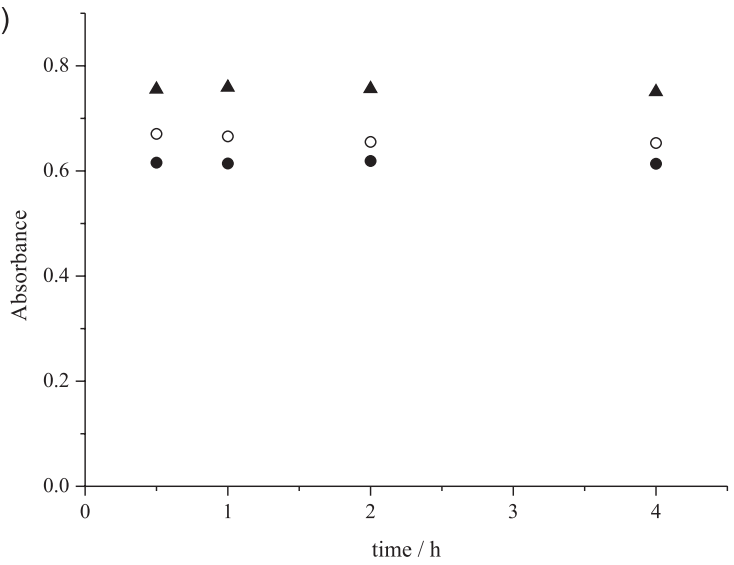

Figure 1. (a) Time dependence of silver plasmon absorbance after the reduction with formaldehyde using $\mathrm{NaOH}$ : $(\bullet) 0.010 \mathrm{~mol} \mathrm{~L}^{-1}$, (○) $0.050 \mathrm{~mol} \mathrm{~L}^{-1},(\boldsymbol{\Delta}) 0.10 \mathrm{~mol} \mathrm{~L}^{-1},(\triangle) 0.20 \mathrm{~mol} \mathrm{~L}^{-1},(\mathbf{\square}) 0.30 \mathrm{~mol} \mathrm{~L}^{-1}$, and ( $\square$ ) $0.40 \mathrm{~mol} \mathrm{~L}^{-1}$; (b) time dependence of silver plasmon absorbance after the reduction with formaldehyde using $\mathrm{NaHCO}_{3}:(\bullet) 0.010 \mathrm{~mol} \mathrm{~L}^{-1}$, (○) $0.050 \mathrm{~mol} \mathrm{~L}^{-1},(\boldsymbol{\Delta}) 0.10 \mathrm{~mol} \mathrm{~L}^{-1},(\triangle) 0.20 \mathrm{~mol} \mathrm{~L}^{-1}$, (口) $0.50 \mathrm{~mol} \mathrm{~L}^{-1}$; (c) time dependence of silver plasmon absorbance after the reduction with formaldehyde using TEA: (•) $0.05 \mathrm{~mol} \mathrm{~L}^{-1}$, (○) $0.10 \mathrm{~mol} \mathrm{~L}^{-1}$, (A) $0.50 \mathrm{~mol} \mathrm{~L}^{-1}$

\section{$U V$-visible absorption spectra}

The absorption spectra of silver particles are presented in Figure 2. The absorption maximum corresponding to borohydride reduction occurs at wavelength $\lambda_{\text {max }} c a .400 \mathrm{~nm}$. The absorption maxima related to formaldehyde reduction are shifted to longer wavelengths depending on the base employed: $\lambda_{\max } c a .412 \mathrm{~nm}$ for $\mathrm{NaOH}$ and TEA, $\lambda_{\text {max }} c a$. $425 \mathrm{~nm}$ for $\mathrm{NaHCO}_{3}$. The shifts in the $\lambda_{\text {max }}$ of the silver plasmon to longer (red shift) and shorter wavelengths (blue shift) have already been described in the literature. ${ }^{22,24,25}$ There are several reasons for these effects: electron density on the surface of nanoparticles, irregular shape and size of nanoparticles, media constants of solutions, refraction coefficients, etc.

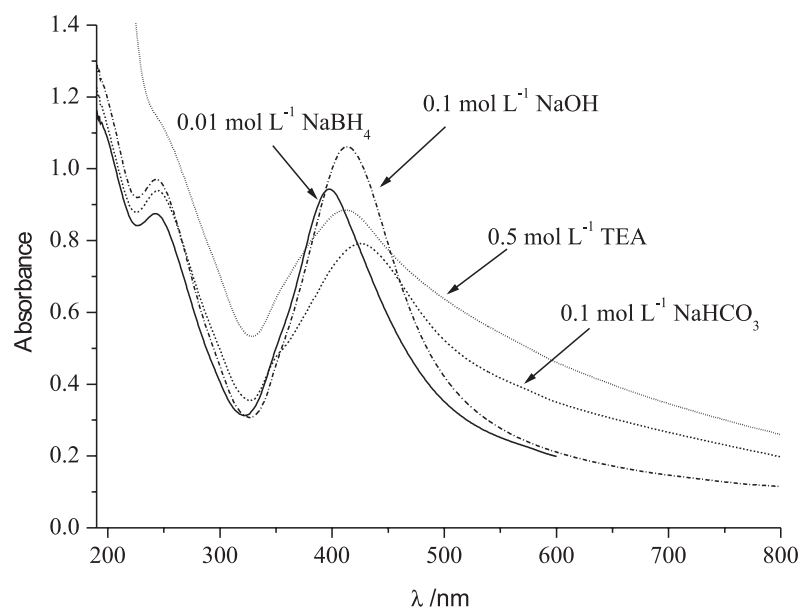

Figure 2. UV-visible absorption spectra of silver particles produced under different conditions.

Besides the shifts, broadening of the plasmon peak was also observed, which is in agreement with the findings of other authors. ${ }^{11,16}$ Such broadening might be caused by the aggregation of silver particles. The narrowest peak belongs to silver particles reduced by $\mathrm{NaBH}_{4}$. The other silver peaks become broader in accordance with the alkaline agents used in combination with formaldehyde: $\mathrm{NaOH}<$ TEA $<\mathrm{NaHCO}_{3}$.

In addition, there is a band at about $\lambda_{\text {max }}=250 \mathrm{~nm}$ in the absorption spectra (Figure 2), which most likely originates from light scattering on montmorillonite particles. The absorption band at around $300 \mathrm{~nm}$, which has been attributed to residual $\mathrm{Ag}^{+}$ions ${ }^{14}$ or to the existence of $\mathrm{Ag}$ nanoparticles smaller than $2 \mathrm{~nm},{ }^{25}$ was not found at all.

Based on the data mentioned above, the following can be said. Borohydride reduction is much faster than that by formaldehyde, and thus silver particles are expected to be smaller, as indicated by the narrower absorption peak and the shorter $\lambda_{\max }$. As the concentration of formaldehyde was identical in all experiments, the concentration of hydroxide ions should be a key parameter for the formaldehyde reduction rate (see reactions 1 and 2). Taking into account the strength of the bases (TEA with $\mathrm{pK}_{\mathrm{b}}=6.24$ and $\mathrm{NaHCO}_{3}$ 
with $\mathrm{pK}_{\mathrm{b}}=7.65$ ), the concentration of hydroxide ions in the aqueous solutions of the weak bases can be estimated from the well-known equation: $\mathrm{pOH} \approx 0.5\left(\mathrm{pK}_{\mathrm{b}}-\log \mathrm{c}_{\mathrm{B}}\right)$, where $\mathrm{c}_{\mathrm{B}}$ is the concentration of the weak base. The calculated concentration of $\mathrm{OH}^{-}$ions, $\mathrm{c}_{\mathrm{OH}}$, decreases in the order: $\mathrm{NaOH}\left(\mathrm{c}_{\mathrm{OH}} \approx 10^{-1} \mathrm{~mol} \mathrm{~L}^{-1}\right)>\mathrm{TEA}\left(\mathrm{c}_{\mathrm{OH}} c a \cdot 10^{-3.3} \mathrm{~mol} \mathrm{~L}^{-1}\right)>$ $\mathrm{NaHCO}_{3}\left(\mathrm{c}_{\mathrm{OH}} \approx 10^{-4.3} \mathrm{~mol} \mathrm{~L}{ }^{-1}\right)$, which is consistent with the order of absorption band broadening. For comparison, $\lambda_{\text {max }}$ values increase in the order: $\mathrm{NaBH}_{4}<\mathrm{NaOH} \approx \mathrm{TEA}<$ $\mathrm{NaHCO}_{3}$ Therefore, it can be assumed that the size of silver particles increases in the order $\mathrm{NaBH}_{4}<\mathrm{NaOH}<\mathrm{TEA}<$ $\mathrm{NaHCO}_{3}$. The particles diameter and their dispersity were further investigated by TEM.

\section{TEM study}

TEM micrographs of silver particles deposited on montmorillonite surface are shown in Figure 3, together with the corresponding SAED patterns as insets. In the SAED patterns, which are compared to the XRD diffraction patterns in Figure 4, crystalline cubic Ag and montmorillonite were detected. The apparent miss of nonbasal peaks of montmorillonite in SAED against XRD is due to the strongly preferred orientation of montmorillonite in TEM samples, which were prepared by sedimentation from suspension. The diffraction peaks of $\mathrm{Ag}$ are not well defined, which suggests a number of structural defects.

In addition, a diffraction peak corresponding to $\mathrm{AgO} /$ $\mathrm{Ag}_{2} \mathrm{O}$ was observed in the sample $\mathrm{Ag}-\mathrm{MMT} / \mathrm{F}-\mathrm{NaHCO}_{3}$.
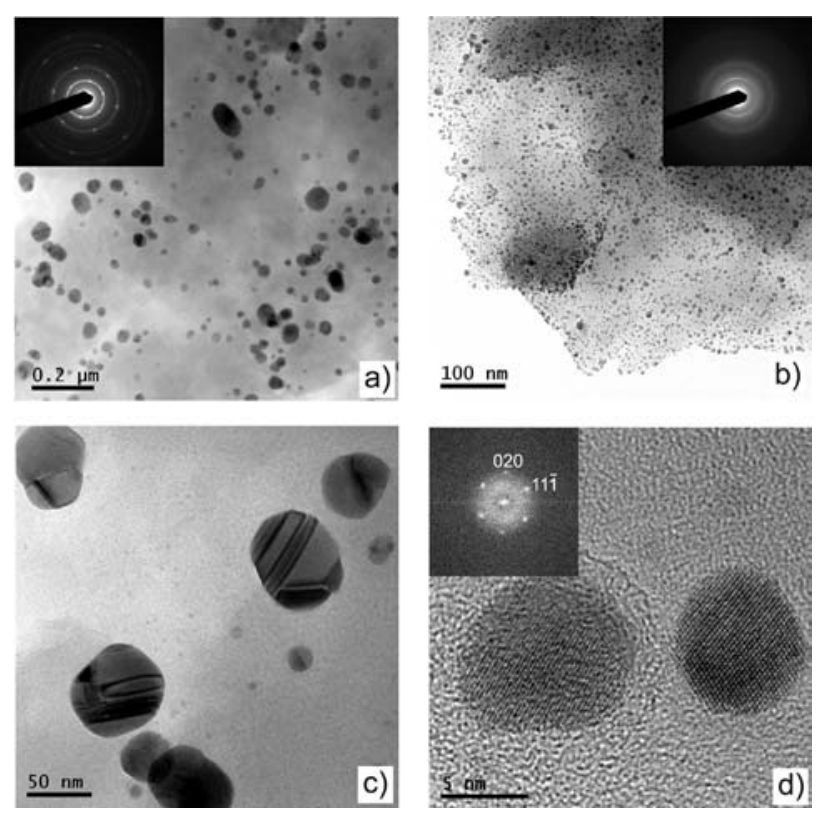

Figure 3. TEM micrographs of silver particles on montmorillonite. (a) Ag particles prepared by reduction with $\mathrm{F}-\mathrm{NaOH}$, (b) $\mathrm{NaBH}_{4}$, (c) twinning of Ag particles prepared by reduction with $\mathrm{F}-\mathrm{NaOH}$, (d) Ag crystal along [101] in Ag-MMT/F-NaHCO . $^{\text {. }}$

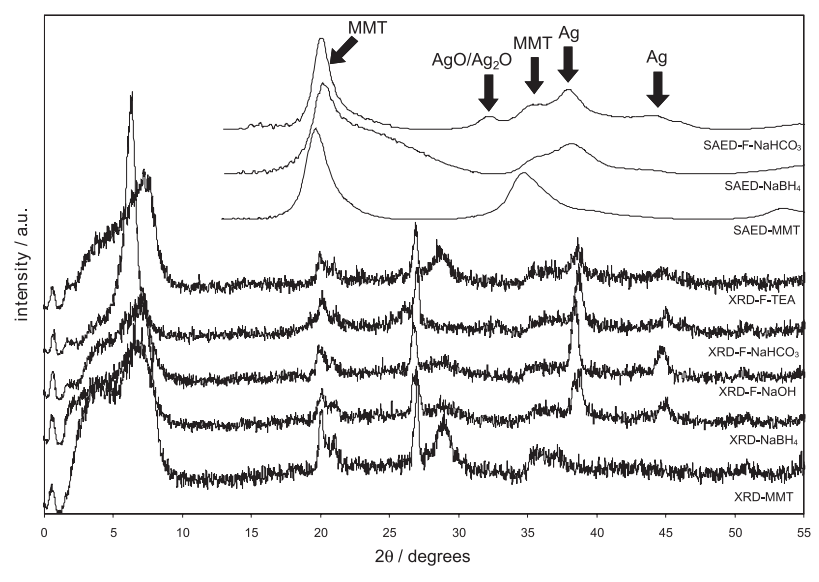

Figure 4. XRD and SAED patterns of Ag-MMT nanocomposites.

This peak very likely indicates the presence of $\mathrm{Ag}_{2} \mathrm{O}$ as a result of incomplete reduction according to reaction 2 . The fact that the oxide is not found in the SAED patterns of $\mathrm{Ag}-\mathrm{MMT} / \mathrm{NaBH}_{4}$ (Figure 4) suggests that silvermontmorillonite composites are stable against oxidation. The composites were repeatedly analyzed by TEM during five months after their preparation. They were stored in common Eppendorf tubes, in the dark, at room temperature.

The size distribution of silver nanoparticles was quantified using images in the $100 \mathrm{~nm}$ scale. About 150 particles were analysed for each sample. As the particles are more or less isometric (Figure 3), their size can be represented by the diameter of a circle with the same area. The sizes were plotted into a histogram with a $1 \mathrm{~nm}$ interval to characterize the size distribution of silver nanoparticles (Figure 5). Statistics was calculated on the diameters as well as their logarithms. Generally, if the distribution is plotted against a logarithmic scale, the maxima are closer to a Gaussian curve and the statistical results (Table 1) appear more meaningful than those based on a linear scale.

Table 1. Basal $d_{001}$ spacings of MMT in Ag-MMT nanocomposites

\begin{tabular}{lcc}
\hline MMT sample & Reduction procedure & $\mathrm{d}_{001} / \mathrm{nm}$ \\
\hline MMT & none & 1.22 \\
$\mathrm{Ag}^{+}$-MMT & none & 1.30 \\
Ag-MMT & F-NaOH & 1.26 \\
Ag-MMT & $\mathrm{F}^{-N a H C O}$ & 1.26 \\
Ag-MMT & F-TEA & 1.39 \\
Ag-MMT & $\mathrm{NaBH}_{4}$ & 1.25 \\
\hline
\end{tabular}

F: Formaldehyde.

The reduction with formaldehyde leads to a wide particle size distribution (3-102 $\mathrm{nm}$ ) and a lower dispersion on the MMT surface (Figure 3a). The reduction with 
(a)

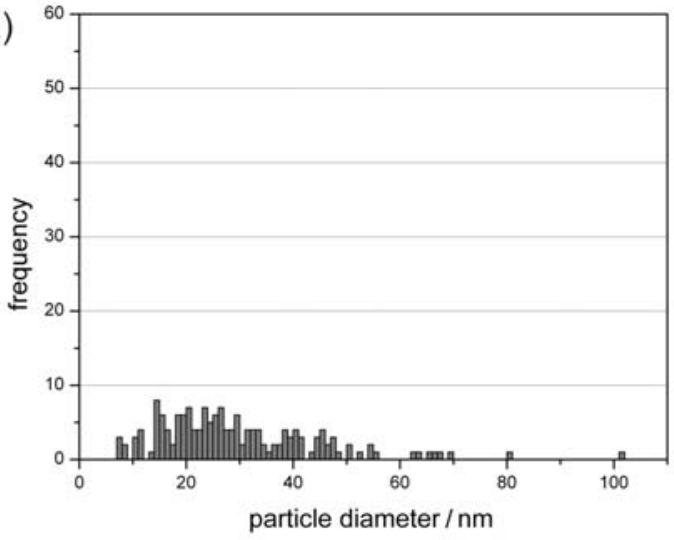

(c)

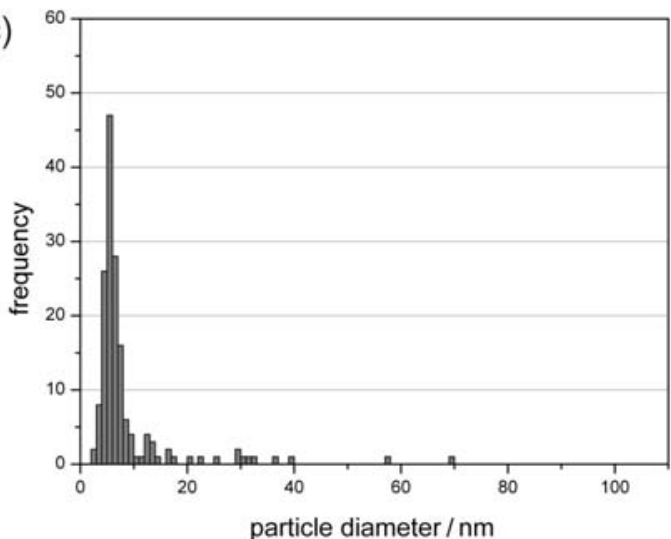

(b)

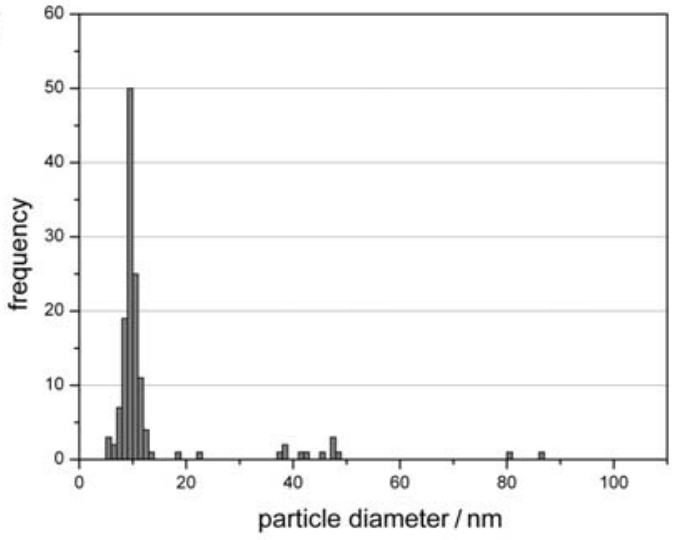

(d)

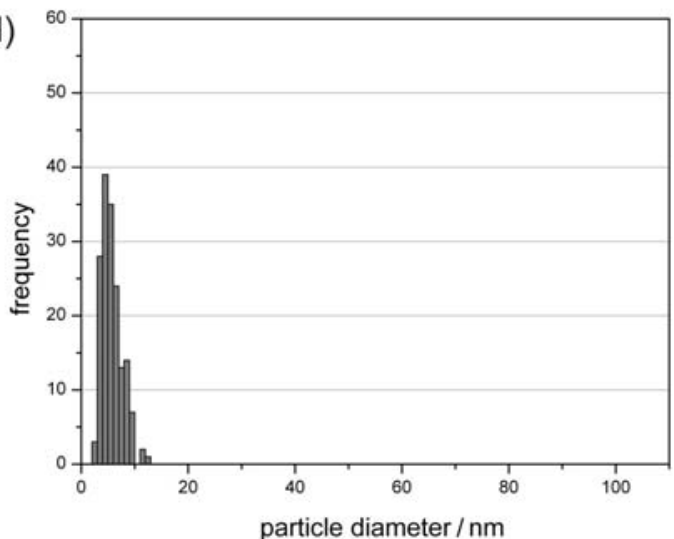

Figure 5. Size distribution histograms of silver particles in silver-montmorillonite nanocomposites prepared by the reduction with: (a) formaldehyde + $\mathrm{NaOH}$, (b) formaldehyde $+\mathrm{NaHCO}_{3}$, (c) formaldehyde $+\mathrm{TEA}$, and (d) $\mathrm{NaBH}_{4}$.

$\mathrm{NaBH}_{4}$ produces silver nanoparticles with sizes from $3 \mathrm{~nm}$ to $13 \mathrm{~nm}$ (the mean size is $5.4 \mathrm{~nm}$ ), highly concentrated and evenly dispersed on MMT (Figure 3b). The statistical data are summarised in Table 2. In comparison with other authors, ${ }^{4,14,18}$ the particle size distribution is quite narrow. For the production of particles with a diameter range of several nanometers, ${ }^{11}$ the method of $\mathrm{NaBH}_{4}$ has to be further optimised.

The particle size distributions correspond well with the spectral band broadening (Figure 2), except of the sample prepared by reduction with formaldehyde and $\mathrm{NaOH}$.
According to the absorption spectra of this sample, the formation of much smaller particles than those observed by TEM was expected. This discrepancy could be explained by the defect microstructure of silver particles, such as twining (Figure 3c), likely originated by their fast formation due to the high hydroxide concentration. The existence of particles composed from $\mathrm{Ag}$ and $\mathrm{Ag}_{2} \mathrm{O}$ should be also expected. These big defective particles absorb light as the aggregates of individual smaller ones welded together; therefore, the absorption band most probably represents these individuals rather than the big particles.

Table 2. Statistics of silver particle size distribution based on logarithms of particle diameter

\begin{tabular}{lccccc}
\hline $\begin{array}{l}\text { Reduction } \\
\text { procedure }\end{array}$ & $\begin{array}{c}\text { Mean / } \\
\mathrm{nm}\end{array}$ & $\begin{array}{c}\text { Standard } \\
\text { deviation } / \mathrm{nm}\end{array}$ & $\begin{array}{c}\text { Mode / } \\
\mathrm{nm}\end{array}$ & $\begin{array}{c}\text { Minimum size / } \\
\mathrm{nm}\end{array}$ & $\begin{array}{c}\text { Maximum size / } \\
\mathrm{nm}\end{array}$ \\
\hline $\mathrm{F}-\mathrm{NaOH}$ & 26.3 & 1.7 & 15 & 7 & 102 \\
$\mathrm{~F}-\mathrm{NaHCO}$ & 11.1 & 1.7 & 10 & 5 & 87 \\
$\mathrm{~F}-\mathrm{TEA}$ & 7.1 & 1.8 & 6 & 3 & 736 \\
$\mathrm{NaBH}_{4}$ & 5.4 & 1.4 & 5 & 3 & 13 \\
\hline
\end{tabular}


XRD study

The XRD study of MMT, $\mathrm{Ag}^{+}-\mathrm{MMT}$, and Ag-MMT nanocomposites was carried out to determine the location of silver particles on montmorillonite. From XRD patterns, montmorillonite $\mathrm{d}_{001}$-basal spacings were calculated (Table 1). The initial increase of MMT $d_{001}$ values from $1.22 \mathrm{~nm}$ for MMT to $1.30 \mathrm{~nm}$ for $\mathrm{Ag}^{+}-\mathrm{MMT}$ confirms the intercalation of silver ions into the interlayer space of montmorillonite. Silver ions intercalation into MMT has been already observed by the increase of $\mathrm{d}_{001}$ values as well as by the release of interlayer cations. ${ }^{2}$

The presence of montmorillonite 001 basal diffractions (Figure 4) indicates that MMT retains its layered structure after the reduction. Silver nanoparticles, due to their size $\geq 3 \mathrm{~nm}$ (see Table 2), cannot be located in the interlayer space and, therefore, are placed on the montmorillonite outer surface as shown on TEM micrographs. The MMT interlayer spacing is occupied by sodium or TEA cations compensating the negative layer charge, and this is documented by montmorillonite 001 diffractions (Figure 4) and $\mathrm{d}_{001}$ values (Table 1).

\section{Conclusions}

In this study, silver-montmorillonite nanocomposites were prepared. The effect of the different reducing agents, such as borohydride and formaldehyde with several alkaline reagents, on the dispersity and size of silver particles supported on montmorillonite surface was demonstrated. The reduction with borohydride produced evenly dispersed silver nanoparticles with sizes ranging from $3 \mathrm{~nm}$ to $13 \mathrm{~nm}$, while formaldehyde gave rise to particles from $3 \mathrm{~nm}$ to $100 \mathrm{~nm}$. The contents of Ag in Ag-MMT were equal to $2.4 \mathrm{wt} \%$ and $5.3 \mathrm{wt} \%$ by the use of $\mathrm{NaBH}_{4}$ and formaldehyde, respectively, depending on Ag particle size. In addition, $\mathrm{Ag}_{2} \mathrm{O}$ particles were also found due to the incomplete reduction of $\mathrm{Ag}_{2} \mathrm{O}$ by formaldehyde.

In future studies, we intend to improve the reduction procedure, by which we could prepare silver particles with the size on demand. Silver-montmorillonite nanocomposites will be further tested as catalysts and luminescent materials possibly applicable as nanosensors.

\section{Acknowledgments}

The authors would like to thank Dr. M. Valášková (Centrum of Nanotechnology, VŠB-Technical University of Ostrava) for the measurement of XRD patterns. This work was supported by the Ministry of Education, Youth and Sport of the Czech Republic (MSM 6198910016).

\section{References}

1. Kwiatkowski, K. C.; Lukehart, C. M.; Nanostructured Materials and Technology, Nalwa, H. S. ed., Academic Press: London, 2002.

2. Praus, P.; Turicová, M.; Valášková, M.; J. Braz. Chem. Soc. 2008, 19, 549.

3. Valǎšková, M.; Martynková, G. S.; Lešková, J.; Čapková, P.; Klemm, V.; Rafaja, D.; J. Nanosci. Nanotechnol. 2008, 8, 3050.

4. Ayyappan, S.; Subbanna, G. N.; Gopalan, R. S.; Rao, C. N. R.; Solid State Ionics 1996, 84, 271.

5. Patakfalvi, R.; Oszkó, A.; Dékány, I.; Colloids Surf., A 2003, $220,45$.

6. Temgire, M. K.; Joshi, S. S.; Radiat. Phys. Chem. 2004, 71, 1039.

7. Kapoor, S.; Langmuir 1998, 14, 1021.

8. Hua, B.; Qiu, J.; Shimotsuma, Z.; Fujita, K.; Hirao, K.; J. Mater. Sci. 2005, 20, 644.

9. Sun, L.; Zhang, Y.; Dang, H.; Mater. Lett. 2003, 57, 3874.

10. Plieth, W., Dietz, H.; Anders, A.; Sandmann, G.; Meixner A.; Weber M., Kneppe H; Surf. Sci. 2005, 597, 119.

11. Zhang, W.; Qiao, X.; Chen, J.; Wang, H.; J. Colloid Interface Sci. 2006, 302, 370.

12. Ullah, M. H.; Il, K.; Ha, C. S.; Mater. Lett. 2006, 60, 1496.

13. Pastoriza-Santos, I.; Liz-Marzán, L. M.; Pure Appl. Chem. 2000, $72,83$.

14. Wang, H.; Qiao, X.; Chen, J.; Wang, X.; Ding, S.; Colloids Surf., A 2005, 256, 111.

15. Chou, K. S.; Chou, Ch. Y.; Mater. Chem. Phys. 2000, 64, 241.

16. Hsu, S. L.; Wu, R. T.; Mater. Lett. 2007, 61, 3719.

17. Sun, X.; Luo, Y.; Mater. Lett. 2005, 59, 3847.

18. Panáček, A.; Kvítek, L.; Prucek, R.; Kolář, M.; Večeřová, R.; Pizúrová, N.; Sharma, V. K.; Nevěčná, T.; Zbořil, R.; J. Phys. Chem. B 2006, 110, 16248.

19. Madejová, J.; Arvaiová, B.; Komadel, P.; Spectrochim. Acta, Part A 1999, 55, 2467.

20. Varian Techtron Pty. Ltd.; Analytical Methods for Flame Spectrometry. Varian: Springvale, 1979.

21. Lábár, J. L.; Microsc. Microanal. 2002, 16, 21.

22. Wilcoxon, J. P.; Martin, J. E.; Provencio, P.; J. Chem. Phys. 2001, 115, 998.

23. Czechoslovakia State Standard; ČSN 720101, Basic Analysis of Silicates. Decomposition. Prague, 1974.

24. Jiang, Z. J.; Liu, Ch. Y.; Liu, Y.; Appl. Surf. Sci. 2004, 233, 135.

25. Zhao, K.; Yao, J.; Mater. Lett. 2006, 60, 3826.

Received: September 2, 2008

Web Release Date: July 17, 2009 